\title{
The relationship between habits and motor skills in humans
}

Yue Du; John W. Krakauer ${ }^{1,2,3}$; Adrian M. Haith ${ }^{1}$

Departments of ${ }^{1}$ Neurology and ${ }^{2}$ Neuroscience, Johns Hopkins University School of Medicine, Baltimore, USA, 21287. ${ }^{3}$ Santa Fe Institute, Santa Fe, USA

Corresponding author: Yue Du; ydu27@jhmi.edu

\begin{abstract}
How do habit and skill relate to one another? Among many traditions of habit research, we suggest that 'slip-of-action' habits are the type most likely to relate to motor skill. Habits are traditionally thought of as a property of behavior as a whole. We suggest, however, that habits are better understood at the level of intermediate computations and, at this level, habits can be considered equivalent to the phenomenon of automaticity in skill learning - improving speed of performance at the cost of flexibility. We also consider the importance of habits in learning complex tasks given limited cognitive resources and suggest that deliberate practice can be viewed as an iterative process of breaking and restructuring habits to improve performance.
\end{abstract}

Keywords: Habit; Skill; Automaticity; Reward; Outcome devaluation; Slips of action; Stimulusresponse association; Cognition; Practice 


\section{Highlights}

- The term 'habit' is used to describe a diverse range of behavioral phenomena. Habits are almost universally interpreted in terms of a stimulus-response (S-R) association that becomes obligatory through repetition.

- A 'slip-of-action' habit occurs when a particular action is erroneously selected in response to an imperative stimulus. This type of habit is likely to be the most relevant to skill.

- Most behaviors are not the result of a single simple S-R association but instead are generated through multiple intermediate computations. Any of these intermediate computations could become habitual, leading to qualitatively different types of habitual behavior.

- When couched at the level of intermediate computations, habit can be considered to be equivalent to the phenomenon of automaticity in skill learning - improving the speed of action selection at the cost of flexibility.

- Habits are essential for learning and performing complex skills because they enable us to perform particular aspects of a skill automatically, thus allowing cognitive resources to be applied to other aspects of the skill that requires deliberation and flexibility.

- Deliberate practice, a key principle in the acquisition of expert performance, can be viewed as the process of iteratively improving a skill by temporarily breaking and then replacing habits with improved versions. 


\section{Outstanding Questions}

- Can distinct types of habit be dissociated within a single behavior? Is it possible to alter which aspects of a behavior become habitual based on practice conditions?

- Can the characteristics of automaticity established in skill learning studies be explained in terms of intermediate computations becoming habitual?

- Under what circumstances can a habit be altered or broken?

- How integral are habits to learning complex skills, and, if so, what are the implication of this for how to best practice to acquire a new skill?

- Are there distinct neural mechanisms for automatization and slips of action that differ from other more commonly studied forms of habit? 


\section{How are skill and habit related?}

An often-quoted passage from William James states: 'When we look at living creatures from an outward point of view, one of the first things that strike us is that they are bundles of habits' [1]. However, among the examples of habit that James offered were walking, swimming, and playing piano - things which we nowadays think of instead as examples of skill. Although habits and skills have come to be viewed as distinct phenomena, they share a longstanding philosophical and scientific history [2,3], and to this day are thought to have fundamental similarities [4-7]. We still, however, lack a satisfactory understanding of exactly how they are related to one another, either computationally or neurobiologically. This is well exemplified by the many ways in which these terms have been juxtaposed over the years: 'habit of skill'[1], 'habit and skill'[8], 'habit is a learned skill' [3], 'skills are thought to be a component of a habit' and 'skill aspects of habits'[9], and 'habitual skill' [10].

In modern usage, the terms 'habit' and 'skill' seem to be easy to distinguish: driving the same route each morning from home to work is a habit, but driving the car itself is a skill; drinking coffee whenever you sit down to write a paper is a habit, while making the perfect espresso and carrying it to your desk without spilling it are skills. In fact, the distinction between skills and habits has at times been thought to be so evident that skills could be defined by way of contrast to habits $[11,12]$. However, there appear to be numerous parallels between skills and habits: both are acquired rather than being innate [1], both are classified under procedural memory [13], both are claimed to involve the striatum $[5,14]$, and both have been related to reinforcement learning [15-19]. These and other parallels have prompted many to speculate that skill and habit may in fact reflect different aspects of the same underlying mechanism that changes how a task is represented and accomplished (e.g., [5,6,20]).

How might we reconcile these conflicting views of the relationship between habits and skills? Is there a sense in which skills and habits can be considered to be equivalent? Should habits be viewed as a special type of skill, or skills as a special type of habit? In this review we focus on understanding motor skills and their relationship to habits. We survey current conceptualizations of both skill and habit and highlight their points of contrast and converge.

\section{Skill}

\section{Acuity, selection, and speed}

Motor skill is something that we clearly recognize when we see it. Examples range from innate skills that we often take for granted, such as walking and reaching [21-23], to everyday skills (e.g., driving or touch-typing) that most of us acquire later in life, to skills that only a few people possess at an elite level, such as playing the violin. Formally defining motor skill and determining what behaviors should qualify as being skilled has not proven straightforward and remains a contentious topic [24]. An uncontroversial definition might be that a skill is an acquired capability to successfully achieve a task goal. When the task itself has an emphasis on movement, it can be referred to as motor skill [8,25-27]. It is by no means clear that this definition helps us to gain any general insights about skill, however. What it takes to perform a task or achieve a goal successfully can vary greatly from one task to the next. Are there unifying features and principles that are common across skills? Although unlikely to be exhaustive, laboratory-based approaches have identified several specific aspects that seem to be characteristics of most motor skills (Figure 1). 
One crucial aspect of motor skill is being able to execute an action accurately and precisely $[28,29]$; for example, hitting the bullseye on a dartboard with minimal scatter. It is impossible to perform exactly the same action repeatedly [30], but skilled performers are consistently able to achieve lower variability, even when moving very quickly - an attribute that has been termed 'motor acuity' [29]. It remains unclear exactly what enables skilled performers to move with greater precision than others. Potential reasons include improved online feedback corrections [31,32], improved acuity of sensory information that guides movement [33], or an improved signal-to-noise ratio in the neural territory responsible for generating movement [25,32].

Being skilled is not purely about precise execution of movement, however. Skilled performers also consistently make good choices about which action to execute, often in response to external cues. It is not surprising that a professional soccer player can perform a pass or a shot accurately, but an elite player will also be able to scan the complex and ever-changing game situation, pick out the right pass among many, and execute it at the right moment. In abstract terms, this action-selection aspect of skill amounts to translating a stimulus and/or goal to a specific response - a process that occurs for high-level decisions such as choosing between options of whether to pass or shoot the ball, and for lower-level aspects of movement such as specifying the timing and force of the kick. The superior performance of skilled individuals is in large part attributable to them selecting better actions at one or more levels of a task [34-37].

A further vital but often overlooked aspect of skill is the ability of selecting the right action quickly. Selecting the perfect pass to a teammate will not be of any benefit if a defender can approach and block you by the time you have decided what to do. Seemingly slow movements such as riding a bike at low speed also demand quick responses to small events like a bump in the road or a gust of wind. Being able to select a suitable action rapidly is therefore another crucial aspect of skill. Indeed, in simple tasks, speed may be the sole metric of skill, with skill level often quantified through the reaction time or task-completion time.

More generally, the appropriateness of the action you are able to select will depend on how much time is invested in making the selection. Action selection and speed can be related through a speed-accuracy trade-off [38] and more skilled performers will have a more favorable speed-accuracy trade-off than less skilled performers; they will take less time to select a suitable action, or will select better actions if allowed only limited time [39] (this speed-accuracy tradeoff for action selection should not be confused with an analogous speed-accuracy trade-off for execution whereby faster movements also tend to be less accurate and less precise $[29,40]$ ).

\section{Simple versus complex skills}

These three fundamental facets of skill - acuity, selection and speed - have generally been studied in relatively simple laboratory tasks that involve key presses with the fingers or planar reaching movements [25]. A recurring question in motor learning research, however, is whether it is possible to translate insights from such laboratory tasks to real-world skills outside the laboratory (Figure 2). Real-world skills differ from laboratory-based tasks in several ways. Compared to the button-presses and reaching movements that are ubiquitous in laboratorybased tasks, many skills, such as juggling, pose the challenge of controlling and coordinating whole-body movements and in doing so one must contend with the problem of many redundant degrees of freedom [30]. Real-world skills also involve a wider range of conditions and contexts, as well as a much bigger set of potential actions to choose between: a soccer player needs to 
take into account the flight of the ball, the locations of the other players and where they might be in the future so as to make an appropriate decision about what to do next. Furthermore, realworld tasks usually involve a much richer, dynamic interaction with the environment that alters the context of our future actions [41-43]; for example, choosing a particular pass will affect the behavior of other players which will, in turn, affect our own action choices down the line. Perhaps because of this runaway increase in complexity, reaching a high level of performance in complex, 'real-world' skills requires years of practice, whereas in laboratory-based tasks learning may reach ceiling in a few minutes or, at most, a few hours.

Another distinguishing facet of complex tasks is that they tend to require greater involvement of cognition than simple tasks [44]. Indeed, there is an emerging appreciation of the fact that complex motor skills are richly cognitive [27,45-48] - comparable to skills such as speaking a foreign language or playing chess. For example, professional soccer players are thought to intelligently read the field [49], perhaps similarly to the ability of chess masters to read board positions [50]. Considerable phenomenological evidence supports the idea that cognition is crucial to performing advanced motor skills (e.g., $[24,45,51])$, and allows us to flexibly select and control actions to achieve a goal under different circumstances. For example, when encountering changes in an environment, we are able to use cognitive strategies to adjust welllearned actions to counter the change [52]. This cognitive core suggests that motor and cognitive skills are more alike than has often been presumed in the past (also $[27,48]$ ).

Given the significant differences between simple laboratory tasks and more complex realworld tasks, it is debatable whether studying learning in laboratory tasks can provide much insight into how complex tasks are mastered (e.g., $[53,54]$ ). It would be difficult to understand the principles of chess mastery by studying how people learn tic-tac-toe. Complex skills are considerably more challenging to study, both technically and conceptually. Across many domains, greater and greater volumes of data are becoming available, raising the possibility of strongly data-driven methods for studying real motor skills that are acquired and improved over longer time-periods [55-60]. However, it is not clear whether such big-data approaches will be able to provide more fundamental insights into why and how improvements in performance take place. An alternative is to design well-controlled laboratory-based tasks that better incorporate crucial aspects of complex skills, such as redundant degrees of freedom, dynamic interactions with the environment, changing contexts, and broader action repertories ([61-63]; also [64,65]). Bridging the gap between reduced laboratory-based tasks and complex, real-world skills remains a considerable challenge, and is an intriguing and important issue for future work.

Although complex skills differ in many respects from simplified laboratory-based tasks, the components of skill identified in laboratory-based studies are nevertheless likely to still be important in complex tasks (Figure 1): executing an action precisely and being able to select the right action as rapidly as possible are equally important when playing the violin as when performing an arbitrary visuomotor association task in a laboratory setting. The action-selection problem may be richer and more challenging for the former, but the trade-off between speed and accuracy remains fundamental to performing any task, and improving this trade-off is likely to be at the heart of how people become skilled at complex tasks as well as at simple ones.

Habit

Habit as an obligatory stimulus-response (S-R) association 
The term 'habit' has been defined and used in many different ways throughout neuroscience and psychology, and encompasses a broad variety of behavioral phenomena from lifestyle habits, such as going to the gym, to movement habits like typing an ATM number. Despite this diversity, the tendency has been to try to explain all habitual behaviors within a single conceptual framework, namely as a learned S-R association that has, through repetition, become obligatory. Despite the appealing universality of this $S-R$ framing, it is unlikely that it can capture the many qualitatively distinct behavioral phenomena described as 'habits' (Figure 3 and Box 1).

\section{Habits in free-operant conditioning}

Much of how habits are currently conceptualized and understood, particularly their neural basis, derives from the study of rodent behavior in free-operant learning paradigms $[66,67]$. In a standard experimental procedure, rats learn that pressing a lever will earn a food reward. Whether or not this lever-pressing becomes habitual is assessed by how frequently the animal chooses to engage in the behavior after the usual food reward is either withheld or is changed to be noxious - a process termed 'reward devaluation'. If the rat reduces the frequency of lever pressing, as is appropriate given the devaluation of the outcome, then its behavior is said to be goal-directed. By contrast, if the rat continues to frequently press the lever, then its behavior is not considered to be goal-directed and is instead habitual. With greater repetition, rat behavior transitions from initially goal-directed to habitual. This transition is generally explained in terms of the formation of a direct $S-R$ association $[68,69]$. The stimulus in this case is usually assumed to be some static feature of the environment such as the presence of the lever, and the response that is invariably triggered is the act of pressing the lever.

Although this paradigm is often thought to model human life habits of engaging in particular behaviors such as drinking coffee when writing or snacking when watching a movie, as well as pathological habits including addictive and compulsive behaviors [20,70-72], the general applicability or relevance of this reward-devaluation approach is questionable. Rodents seem to develop habitual behaviors of this type only when the task involves a static context, only one possible response, and its corresponding reward [73,74] - a very restrictive scenario. Attempts to apply reward-devaluation protocols to examine habit formation in humans have also been largely unsuccessful: human participants readily adjust their behavior in a goal-directed manner following reward devaluation despite extensive repetitions ([75]; but see [76] for a successful case). The discrepancy between rodent and human behavior might be attributable to humans either never forming the habit, or more successfully suppressing the habit owing to superior cognitive control (also [77]).

Even when persistent behaviors are observed after reward devaluation, it does not necessarily indicate the existence of habit. If people do not value the 'reward' that is provided (which might, for instance, be only a virtual image), then devaluing the reward is meaningless. Even if people do value the reward, there may be other hidden incentive outcomes that are never devalued, which can cause persistent behaviors [78]. For example, if our goal was to enjoy the taste of popcorn, continuing to eat stale popcorn (i.e., devalued) when watching a movie may reflect a habit. This persistent behavior, however, may also be driven by the goal to enjoy a more authentic cinema experience, which can be attained regardless of how the popcorn tastes [7981]. Intriguingly, it has been suggested that rats will press a lever not because they want the food reward it delivers, but instead because they value the act of pressing the lever, regardless of any 
reward [82]. If this is the case, continuing to press a lever after the food reward is devalued may not necessarily imply that the behavior is habitual. Moreover, it is also very difficult to determine whether or not a reward has been successfully devalued. For example, informing alcoholics about the long-term detrimental consequences of alcohol consumption may not outweigh the immediate reward available from drinking alcohol. Any residual reward might lead to the appearance of habitual behavior $([83,84]$ for a similar view in non-human animal habits). Finally, persistence of a previously learned behavior after reward devaluation might not be due to habit but could instead result from a failure of goal-directed control because of lack of understanding or misapplication of task rules [20].

Influenced by reward devaluation approaches in rodents, it is often thought that reward is a key driver of habit formation in general. This interpretation also parallels Thorndike's famous law of effect, whereby a response reinforced by a reward will become more likely to be selected in the future [85]. The notions of reward and reinforcement learning have become a dominant lens for interpreting habit formation, and popular theories positing that habit formation is fundamentally about learning the values of different actions in a model-free sense [15]. However, the emphasis on the role of reward in forming S-R associations may be somewhat exaggerated. The tactic of reward devaluation originated as a pragmatic way to study habit formation in rodents, but it is not necessary to transfer this approach over to humans. Instead, one can simply instruct participants to behave one way, then later instruct them to change their behavior and assess whether or not they are able to comply with the change. This reward-free process is consistent with Thorndike's lesser known law of exercise [85], and is more in line with recent computational proposals that reinstate the idea that habits reflect a persistence of how we select actions, rather than in how much value we place on particular actions $[19,86]$.

In summary, free-operant paradigms remain a cornerstone of habit research. However, the scope of such effects appears to be quite narrow in general, and in particular it remains unclear whether habits of this kind are relevant to skill.

\section{Slips of action}

A very different tradition of habit research has focused on so-called 'slips of action' [8789], whereby we habitually select the wrong action during performance of a task. For example, when the app icons on our smartphone become rearranged, we may habitually try to open a particular app by tapping the screen where it used to be located. These slips of action are very naturally explained in terms of an obligatory S-R association: the unwanted response occurs because it is directly triggered by a stimulus. Slip-of-action habits differ from habits in operant conditioning tasks in that multiple potential actions must be available so as to select the wrong action, and the triggering stimulus tends to demand an immediate response. As such, this type of habit is the one most likely related to skill which, as we discussed earlier, involves rapidly selecting a suitable action among alternatives, usually in response to external cues.

Slip-of-action habits are studied in the laboratory using arbitrary visuomotor association tasks $[90,91]$ in which participants learn to associate particular responses (e.g., key presses) to a set of presented stimuli. As participants practice this task, one might expect them to develop a direct association between each stimulus and its associated response, which would presumably lead them to become habitual in generating particular responses to each stimulus $[39,92]$. 
A variety of different approaches have been used to assess whether or not such associations do actually become habitual through practice. One approach, following from the idea that the stimulus should obligatorily trigger the response, is to test whether participants can successfully withhold a previously learned response to a stimulus [75]. Such approaches, however, have had only limited success in identifying habits in human participants ([75]; but see [93] for a successful case). An alternative approach is to test whether participants are able to switch to generating a different response from one that was initially learned [39]. In such cases, participants remain very able to comply with the new mapping, and commit errors at a very low rate $(\sim 5 \%)$ even after having practiced the original association for thousands of trials [94]. Tellingly, however, such low error rates tend to be accompanied by long reaction times $[95,96]$, suggesting that people avoid slips of action by giving themselves more time to respond.

A recent study by Hardwick and colleagues [39] demonstrated that this is indeed the case. Participants were trained on a four-element visuomotor association for up to 20 days, then the responses required for two of the stimuli were switched. Participants had little difficulty learning the revised mapping, but when they were forced to generate their responses very rapidly, they reverted to the originally practiced mapping. Continuously varying the exact amount of preparation time that participants were allowed revealed a stereotyped time-course over which the habitual response was liable to be expressed, peaking 300-600 ms after the stimulus was presented.

Slips of action of this type appear to be potentially very pertinent to skill: motor skills require that a particular action among many is selected rapidly, usually in response to an imperative stimulus. Slips of action occur in exactly this scenario, and seem to instantiate a direct association between a stimulus and a response. Furthermore, it appears that, at least in some cases, this habitual mode of action selection can occur very rapidly - more rapidly than goaldirected actions - and thus enable a superior speed-accuracy trade-off, serving to improve skill, albeit at the cost of flexibility.

\section{Habits beyond simple S-R associations}

The notion that habits can be attributed to a simple S-R association between an external stimulus and an overt behavioral response pervades discussions of habits across a wide range of domains, from frequent responses in operant conditioning paradigms to slips of action and lifestyle habits. How can it be possible that one and the same mechanism could account for these very different types of habitual behavior? The likely explanation is that our behavior is never really the result of a single, direct S-R association. Instead, it is governed by a complex set of processes, some with computations relating to more abstract goals and plans (e.g., 'get coffee') and others relating to lower-level action selection such as which limb to move and how to move it (Figure 4). Lifestyle habits, such as drinking coffee while writing, occur when computations associated with abstract decisions become habitual, whereas slips of action occur when computations associated with lower-level action selections become habitual [88].

Whenever there are intermediate computations between a stimulus and an eventual response, this creates the possibility that the final behavior can become habitual in multiple distinct ways, depending on which of these computations become habitual. A common type of intermediate computation is that a stimulus does not directly trigger a response, and instead triggers selection of a particular goal to be pursued, which in turn triggers selection of an action 
to achieve that goal (Figure 5B) [6,97]. For example, seeing a red light while driving might cue the goal of stopping the car, which is then achieved by pressing the brake pedal. Organizing the behavior as two distinct associations, a stimulus-goal association and a goal-response association, enhances our ability to generalize to different settings: seeing a red stimulus in a context other than driving a car can still evoke the intention of stopping [93], and we can easily slam the brake pedal if a passenger unexpectedly yells 'stop'. Either or both of the stimulus-goal and the goal-response associations could become habitual, which will give rise to different types of habitual behavior. If seeing a red light habitually triggers the goal of stopping, one could still select amongst actions to stop the car in a goal-directed way; conversely, if pressing the brake pedal to stop the car becomes habitual, one could still be flexible about what goal to pursue in the event of a red light.

A stimulus-goal-response organization can be present in many behaviors and can drastically alter how we should interpret the underlying cause of a habitual behavior. For instance, many people might have a habit of drinking coffee whenever they write. A simple interpretation of this habit would be that the act of writing serves as a stimulus, directly triggering the response of drinking coffee (i.e., an S-R association). Alternatively, however, it could be that the act of writing itself tends to habitually elicit feelings of anxiety (perhaps due to a past history of writing to meet impending deadlines). Writing thus acts as a stimulus that effectively creates a new goal of alleviating anxiety (i.e., a stimulus-goal association), and we choose to drink coffee to achieve that goal. This example illustrates the seemingly contradictory idea of a 'goal-directed habitual action' by which a particular stimulus habitually triggers a specific goal which is then pursued in a flexible manner [98-102]. Such a mechanism has been proposed as a more compelling explanation for drug-seeking and other pathological habits, given the flexible ends to which a user might resort to obtain drugs $[74,103,104]$. This 'intermediate-computation' view of habit can also be applied to the free-operant behaviors of animals because there are multiple distinct associations that an animal could learn to guide its behavior, including stimulus-response, stimulus-reward, response-reward, and stimulus-response-reward associations $[84,105,106]$. It remains unclear which of these associations is primarily responsible for the observed habitual behavior.

Beyond the simple idea that goal selection intercedes between a stimulus and response, complex behaviors can involve many other types of intermediate computations that relate to, for instance, chunking of responses [34], task-set selection [107-109], following task rules [110], or pursuing differing goals over varying task levels [111-115], to name a few. If some of these underlying computations become habitual whereas others do not, this will result in some aspects of behavior being habitual and inflexible and others aspects of behavior remaining flexible (Figure 5B,C). Indeed, multiple sources of evidence, from following life routines [116-119], decisionmaking [101,120,121], categorical learning [122], and slip-of-action research [102], have begun to demonstrate that different intermediate computations can become obligatory - each leading to distinct patterns of overt habitual behavior ([123] for evidence in a non-human animal).

In the context of motor control, it has long been appreciated that even simple motor acts involve many intermediate processes and associated computations $[124,125]$ that intercede between the stimulus and the response (Figure 4B). These processes and computations may range from perceiving various aspects of a stimulus [126,127], to setting the motor goal [90], choosing a general class of actions to perform [128-131], selecting which effector to use [132], 
specifying the kinematic details of the movement (e.g., its amplitude, speed, and timing) [133], and finally coordinating muscle activity to bring about the movement $([29,130,131]$; reviewed in $[25,125])$.

Given these distinct intermediate computations, one might expect that motor behavior could be habitual in many different senses, depending on which of these computations becomes habitual. Indeed, several studies have shown that behavior in well-learned motor tasks can be habitual in many different senses, including in the way in which we co-ordinate muscles [134] or effectors [135,136], as well as in the order [137] and tempo [138] with which we generate sequential actions. Parameters of movement such as direction [139], movement speed [140], and even the duration of reaction times [141] show biases towards values that have been frequently selected in the past and these have been likened to habits. Animal work has also demonstrated stereotyped and habitual patterns of movement kinematics in overtrained tasks $[5,142]$. Beyond these motor components, well-established phenomena such as the Stroop and Simon effects also reveal habitual behavior at the level of perceiving and processing different features of a stimulus $[127,143]$. It is likely that these and potentially many other types of qualitatively distinct habits can co-occur in even seemingly simple motor behaviors (Figure 5C).

We conclude that it is more fruitful to think about habits as a property of the intermediate computations that precede response generation (Figure $5 B, C$ ), rather than as a property of the response itself (Figure 5A). In the next sections we consider how this and other insights about habit formation might help us to understand the relationship between habit and skill, both in simple, laboratory-style tasks and in more complex, real-world skills.

\section{The relationship between skill and habit}

\section{Automaticity as the nexus between habit and skill}

Although habit and skill have long been thought to be related, the term 'habit' is, perhaps surprisingly, not commonly used in skill-learning research. Instead, a dominant notion in skill learning is that of 'automaticity'. We are likely all familiar with the experience that performing an initially challenging task becomes easier and seemingly 'automatic' with practice [8]. However, the concept of automaticity itself is challenging to define [144-146]. Automaticity has been characterized in terms of numerous features, including that it is unintentional, unconscious, uncontrolled, effortless, and fast. However, no single one of these features on its own seems to provide a satisfactory hallmark of automaticity: seemingly automatic behaviors do not always possess all of these features [144,146]. Nevertheless, a commonly touted feature of automaticity is inflexibility $[122,146,147]$. That is, it can be difficult to alter a skill once it has been rendered automatic. This suggests a clear parallel between automaticity and habit. Indeed, the terms 'automatic' and 'habitual' are sometimes used interchangeably [72,148] and automaticity, like habit, is often described in terms of formation of a direct S-R association [149]. Thus, it seems very possible that the underlying changes that render a behavior habitual may be one and the same as those responsible for it becoming automatic. In both cases, a particular action comes to be automatically triggered by its associated stimulus. In this sense, being habitual might be considered equivalent to being automatic [80].

As we have discussed in the context of habit, however, most behaviors are not generated through a simple one-step S-R association (Figures 4 and 5). Instead, they are generated based on a complex set of computations that relate a stimulus to an ultimate response. As with habits, 
the term 'automatic' is, in most cases, used to described behavior as a whole. It has, however, been suggested that automaticity should instead be considered to be a property of intermediate computations or processes [150-153]. If this is the case, then whenever multiple computations contribute to an eventual behavior, any one of these computations could become automatic, potentially with distinct consequences for final behavior. For instance, automatizing a particular method for doing mental arithmetic (e.g., adding two three-digit numbers) is qualitatively different from automatically retrieving the answer from memory (e.g., [154]). In both cases, one might reasonably describe the behavior as 'automatic', but the behavior will be very different. From this point of view, it is unsurprising that it is difficult to achieve a consistent definition of automaticity on the basis of properties of behavior as a whole. Instead, automaticity is likely best understood as a property of intermediate computations, from which it follows that habit and automaticity can be considered to be equivalent.

Although automaticity is a hallmark of skills, it is important to emphasize that the potential equivalence between habit and automaticity does not mean that habit and skill are themselves equivalent. Clearly, not all automatic behaviors can be considered to be skills. Furthermore, an important feature of many skills is that they are marked by flexibility $[12,155]$. A skilled musician can perform the same piece of music with different tempos or varying emotional expression [156], or improvise an entirely new piece. Even in daily-life skills such as driving and walking, we can flexibly adjust our movement patterns according to different weather or surface conditions. How does one reconcile the need for flexibility in skilled behavior with the notion that skills become automatic and thus inflexible through practice? This apparent paradox is easily resolvable after recognizing that complex skills never reflect only a single association between stimuli and responses, and instead involve multiple intermediate computations. Some of these computations might become automatic (or, equivalently, habitual), whereas others might remain deliberative, thus ensuring flexibility where it is needed. In line with this view, it has been proposed that a complex skill depends on a combination of habitual and cognitive processes $[45,46,48,81,89,157-159]$. As a result, although a soccer player might exhibit flexibility and creativity in selecting where to pass the ball, they are also likely to be habitual in other respects - for instance they may always kick the ball with their dominant foot.

In short, we suggest that habit can be equated to the concept of automaticity in skill learning, provided that these terms are used to describe a property of intermediate computations or processes underlying a behavior rather than the behavior as a whole. Again, being habitual in no way implies being skilled. An unskilled behavior can become habitual as easily as a skilled behavior. Furthermore, almost all skills require some degree of flexibility and therefore skills likely cannot be entirely habitual (or, equivalently, automatic). The converse, however, is true: automatizing intermediate computations is essential to improving one's skill, largely by accelerating action selection and reducing cognitive demands [6]. As we argue in the next section, balancing these advantages with the need for flexibility is likely crucial for successful skill acquisition, particularly for complex skills.

\section{Habit and automaticity in complex skill acquisition}

As we have pointed out, complex skills are distinguished from simple skills by the scope and variety of stimuli that may warrant a response, as well as by the number of potential actions 
available and the richer dynamics between the actor and the environment. Making particular components of a skill automatic is likely to be crucial for learning complex skills because it liberates scarce cognitive resources that can then be applied to learning other aspects of the skill. A novice soccer player learns to dribble the ball with her head down so that she can focus on the movements of both the ball and her feet. Through practice, her ability to dribble the ball becomes automatic, no longer relying on cognitive resources, and thus she can instead look away from the ball to focus on the movement of her opponents and teammates. With practice, her ability to scan the field will also become automatized, and her cognitive resources can be put to solving other problems. Thus, given the limited cognitive resources available to bring to bear on any given task - a concept often described as bounded rationality $[160,161]$ - her repertoire of subskills must be compiled one at a time.

In general, as we practice a skill, there are two distinct ways in which our performance can continue to improve. Components of skills, that have already become automatized (or, equivalently, have become habitual), are likely not entirely set in stone but can continue to improve with further practice. For example, participants in an arbitrary visuomotor association task become habitual within 4 days of practice but their speed-accuracy trade-off can still improve with more practice [39]. Thus, the role of practice is not simply to automatize ever more components of a skill but also to further improve components that are already automatic. However, the scope of such improvements may be limited and the rate of improvement may be slow (Figure 6B). To achieve bigger leaps in task performance, it may be necessary to qualitatively restructure the way in which we perform the task - for instance, in the high jump, switching from the straddle style to a Fosbury flop brought about changes in the world record that were not achieved by incremental improvements in the straddle style (cf. $[55,162])$. We may also need to reimagine the way we select actions by taking into account additional stimuli, such as the movement of our opponents, or the spin on a tennis ball as we receive it. More drastic changes like this likely require de-automatization by switching from an automatic to a deliberate mode of action selection, before revamping and then re-automatizing this component of the skill. Although this may temporarily worsen performance [55], this process will ultimately raise the ceiling on what performance level is possible. This cycle of switching between deliberate and automatic modes for specific component processes of a skill is likely the essential purpose of deliberate practice [163-165] and distinguishes it from naive practice - mere repetition of a task - which instead only incrementally improves already automatized components (Figure 6A).

Many components of a skill that become automatized early in learning may therefore only be temporary stepping stones on the way to more advanced levels of performance. At some point during learning, almost any automatized association might need to be refined or replaced with something better. How successfully this can be achieved depends on how easy the habit is to break. If the initial habit becomes too ingrained and difficult to break, it will block the path to higher-level performance in the future. A recent study demonstrated such an effect in sequence learning. Participants were trained to 'chunk' a sequence of actions in a particular way. Later, when learning to perform longer and more challenging sequences, participants tended to persist with the initially learned chunking structure, even after 2 weeks of further training and despite 
the fact that alternative chunking structures could have improved their performance [166]. Unfortunately, many of us often build such bad habits during early skill learning. We learn suboptimal solutions and reuse them until they are rendered into persistent habits that impede our progress towards better performance $[167,168]$. This is perhaps the reason why experts reportedly try to avoid acquiring habits in pursuit of high-level performance $[169,170]$ and the supervision of an external coach is almost certainly essential in accomplishing this by providing vigilance against the formation of bad habits.

The path to expertise, therefore, likely involves repeated cycles of building and breaking temporary habits, while at the same time restructuring and adding other habits that will form the foundation of our skills for many years. When acquiring complex skills, we must strike a delicate balance between automatizing particular components of a skill, thereby allowing us to focus our attention on improving other sub-components of the skill and to think at a higher strategic level, while avoiding developing bad habits that may hold us back in the long term. Understanding how habits are formed and how they can be broken, and how an optimal balance is achieved between automaticity and flexibility through practice, will to be crucial for gaining a complete picture of how we acquire expertise under constraints of limited cognitive resources (Outstanding Questions).

\section{Concluding remarks}

We remain some way from a complete understanding of the relationship between skill and habit. Both skills and habits are, in their own rights, vast fields of study. It is likely that not all types of habit are relevant to skill, and that many aspects of skill have no relation to habits. Nevertheless, we argue for convergence between particular types of habit - so-called 'slips of action' - and the notion of automaticity in skilled performance. We suggest that, when viewed as characteristics of individual intermediate computations rather than as emergent properties of behavior as a whole, habit and automaticity can be considered to be equivalent.

Much research on habits and skills has employed simple laboratory-based tasks, often focusing on seemingly elementary behaviors, with the view that the overt simple behavior is either habitual or not (e.g., $[69,75,76,171])$ ), or automatic or not (e.g., $[122,172,173])$ ). However, even the simplest of tasks can involve intermediate computations that give rise to the possibility that behavior could be habitual or (equivalently) automatic in many distinct senses. An important direction for future research is to develop better approaches for characterizing the multicomponential nature of simple behaviors and to understand habit and automaticity in terms of these component computations rather than behavior as a whole.

A more comprehensive understanding of the constituent components of skills and habits at the behavioral level will also be essential for characterizing their neural bases (Outstanding questions). Fine-grained recordings of neural activity may help to clarify the nature and scope of such computations, but making sense of neural activity is likely to also require thorough characterizations of a behavior and corresponding comprehensive behavioral assays $[174,175]$.

Understanding the multitude of computations underlying behavior becomes even more crucial for obtaining a clear picture of how we acquire complex skills, which, owing to the 
constraints of bounded rationality, must depend heavily on habitual/automatized computations. A key direction for future research will be to bridge the current divide between simple laboratorybased tasks and complex real-world skills. This might be achieved by developing better assays to dissect complex skills into their constituent components, and/or by designing more elaborate laboratory-based tasks that begin to manifest the complexity of real-world skills (e.g., including redundant degrees of freedom, dynamic interactions with the environment, and larger sets of possible stimuli, states, and actions). Most likely, progress will depend on a combination of these two approaches.

Finally, although we have focused here on motor skills, the principles discussed here apply equally to purely cognitive skills, such as learning a language or performing mental arithmetic, as they do to motor skills such as playing a musical instrument or playing soccer.

\section{Box 1}

\section{Other traditions in habit research}

Habit is a core concept in many different domains of research $[176,177]$ - not only in animal operant conditioning experiments and slips of action, as described in the main text. One other major tradition of habit research concerns the routines that we repeatedly follow in our daily life. William James offered a striking example of this type of habit: "A very absent-minded person went to the bedroom to dress for dinner, habitually took off one garment after another, and finally went to bed". We often colloquially claim to have habits such as brushing our teeth every night before going to bed, going to the gym every morning before work, or meeting friends at the same coffee shop every weekend. Rituals and compulsive behaviors might also be described as habits of this type [178]. Quantifying this type of habit tends to rely on participant self-assessments and questionnaires $[179,180]$, and does not usually seek to experimentally assess whether or not the behavior is obligatory - in other words, whether it will occur even when it is no longer desired. It is clear that such habits are different in many ways from slip-ofaction or operant conditioning habits - we clearly do not rush in for a work-out simply because we happen to pass the gym. Nevertheless, lifestyle habits of this type have generally been interpreted in terms of the same framework of S-R associations that are used to explain habitual behavior in operant conditioning tasks [148]. In this case, the 'stimulus' might be a location or a particular event in the day, and the 'response' is the activity itself, such as going to the gym. However, the response could also be triggered by some internal goals (e.g., becoming healthy) [181], which implies habits occurring at the level of intermediate computations instead of being a simple $\mathrm{S}-\mathrm{R}$ association (discussed in the main text). Cultivating or eliminating habits of this type is of clear societal importance in terms of public health and consumer behavior. Exactly whether and how such habits relate to slip-of-action habits and operant conditioning habits remains an open question for future research. 
(A)

Precise movement execution

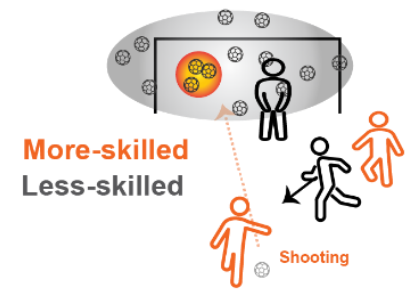

(B)

Action selection

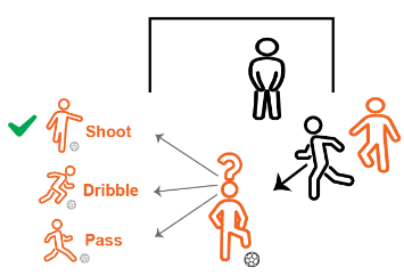

(C)

Speed of selection

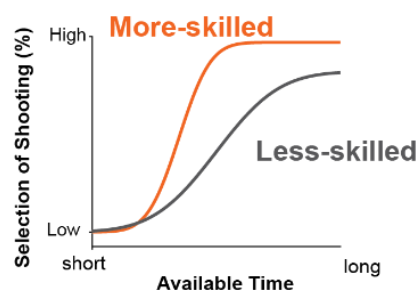

Figure 1: Three aspects that characterize motor skills. (A) Being skilled requires the ability to consistently execute an action accurately and precisely. For example, a more-skilled soccer player can shoot the ball towards the same area on multiple attempts whereas a less-skilled player will have much greater variability. (B) Another feature of skill is to make good choices about which action to execute. When faced with a choice to shoot at goal, pass to a teammate, or dribble with the ball, a skilled player will consistently select the best option. (C) Being able to select an action quickly is another vital aspect of motor skill. Two players may both make the correct choice to shoot, but the more-skilled player will take less time to make that choice. In general, the time course of a decision can be characterized in terms of a speed-accuracy tradeoff which plots how often the best action is selected as a function of the amount of time taken to decide, and more-skilled players will have a more favorable speed-accuracy trade-off.
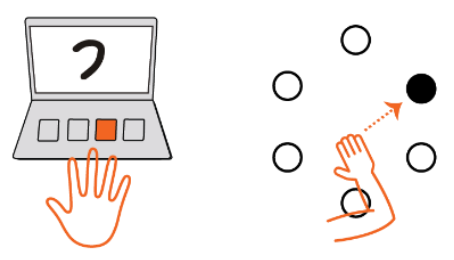

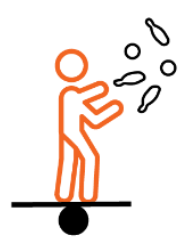

Complexity

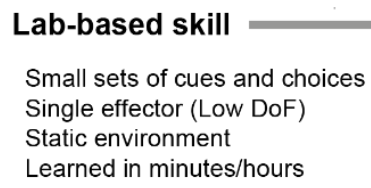

Figure 2: Simple laboratory-based skills versus real-life complex skills. Laboratory-based tasks used to study motor skill typically involve key presses with the fingers or planar reaching movements. Complex skills, by contrast, may require control of multiple body segments (e.g., higher degrees of freedom, DoF), involve a wider range of conditions influencing the choice of action, and have a much bigger set of potential actions to choose from. Unlike simple laboratory-based skills, real-world skills also often involve a rich dynamic interaction with the environment. This increasing complexity is reflected in the extent of practice that is necessary to become skilled in real-life tasks. 
(A)
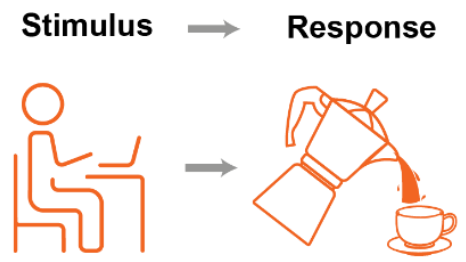

(C)

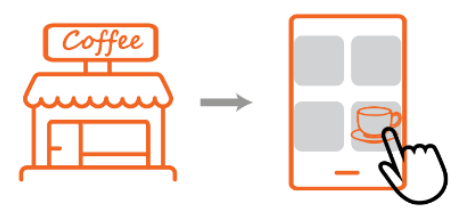

(B)

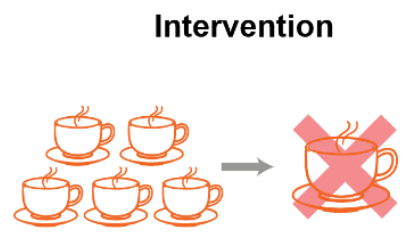

(D)

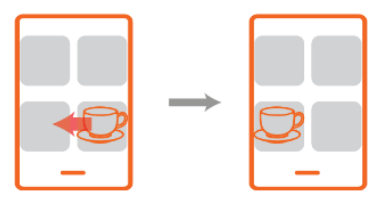

Assessment
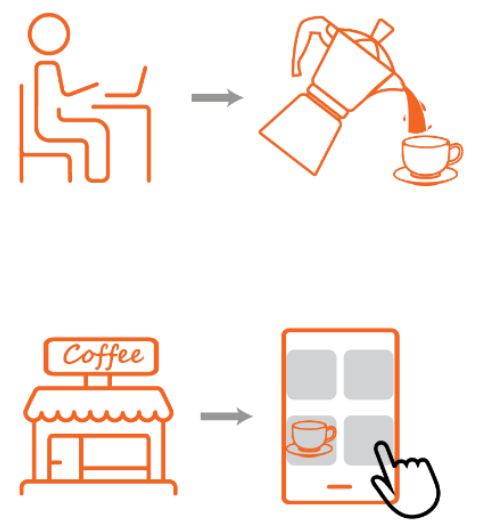

Figure 3: Human habits and experimental approaches for assessing them. (A) One example of a life habit is that people may habitually drink coffee whenever they sit down to write. In this case, writing acts as the stimulus, triggering the response to get and drink coffee. (B) Whether or not this behavior is truly habitual could be assessed using a reward-devaluation approach. The desirability of drinking coffee is reduced by satiation (drinking several cups of coffee) before writing. If sitting down to write still triggers coffee-drinking then coffee-drinking is habitual. (C) Another type of habit is a so-called 'slip of action', whereby an action is rapidly selected and generated in response to an imperative stimulus. Smelling coffee when passing by a coffee shop may cause us to open a coffee-ordering app on our phone and order our own cup. (D) If the icons on our smartphone are rearranged, we may nevertheless habitually tap the old location on the screen. 
(A)

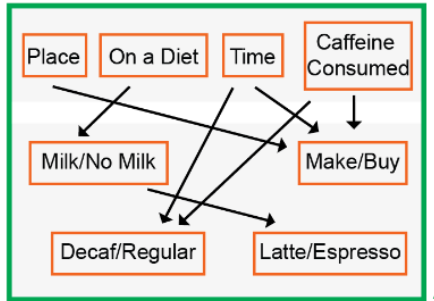

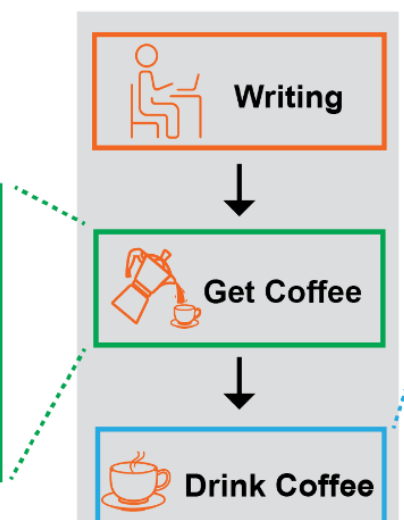

(B)

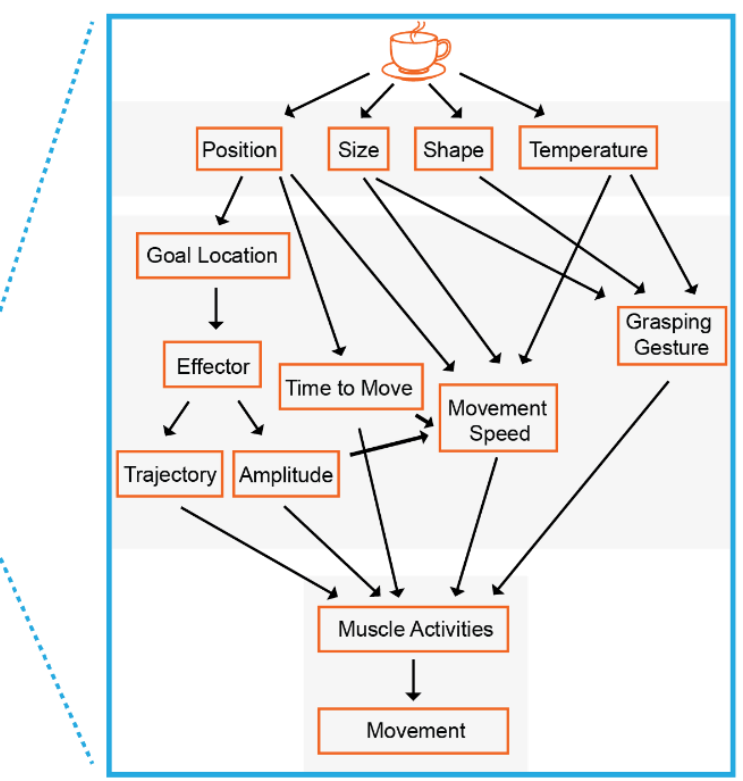

\section{Figure 4: Illustration of intermediate processes and computations underlying a simple} behavior and a simple motor action. A seemingly simple behavior of drinking coffee while writing might be interpreted in terms of a simple-goal-response association ('writing'-'get coffee'-'drink coffee'). (A) Achieving the goal of getting coffee encompasses many interdependent choices about whether to make or buy coffee, what type of coffee to get, whether it should be decaffeinated or regular, and so on. These individual choices collectively dictate the ultimate response to satisfy the goal of getting coffee. Any or all of the computations that determines these choices (represented as arrows in the figure), may become habitual. For example, you might habitually buy a cup of coffee from a local store as you happen to be there; you might habitually order a latte instead of an espresso, even though that you planned to avoid less healthy options; you might habitually add milk to the coffee for a friend even though you know she is lactose intolerant. (B) The act of drinking coffee also involves numerous intermediate processes and associated computations that must occur before the action can be executed. These include setting a motor goal (the location of the target), choosing the effector, planning the trajectory, amplitude, and speed of the movement, and specifying exactly how to physically execute the action (e.g., which muscles to contract). In principle, any of these intermediate computations that are associated with distinct aspects of the reaching action could become habitual. 
(A)

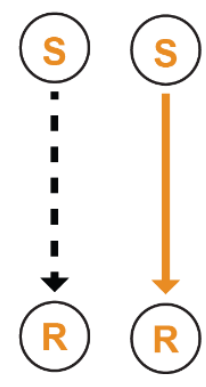

(B)

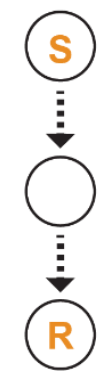

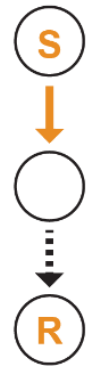

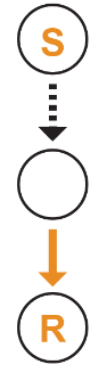

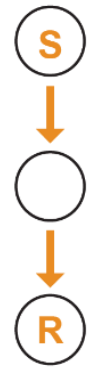

(C)

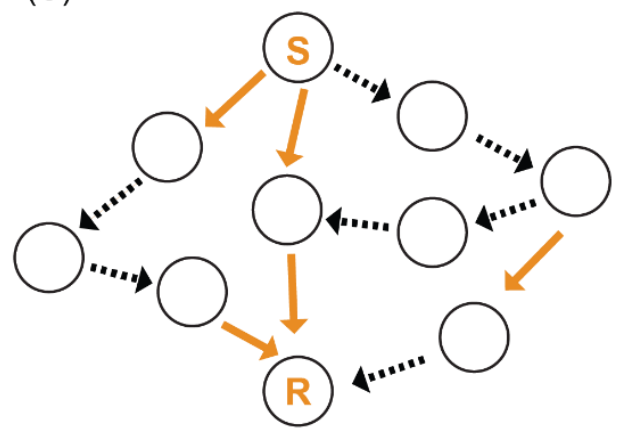

$\ldots$ Non-habitual

Figure 5: Habit beyond simple stimulus-response associations. (A) Habits are often considered within the appealing framework of a simple association between a stimulus $(S)$ and a response (R). A response to a stimulus can be selected either in a non-habitual (goal-directed) (dashed black line) way or in a habitual way (solid orange line). (B) In general, responses are rarely triggered directly by a stimulus, but involve intermediate computations (Figure 4 for an illustrative example). In a simple case involving driving a car, we might need to determine a goal (e.g., stop) that intercedes between a stimulus (e.g., red light) and the response (e.g., press the brake pedal). Either the stimulus-goal or goal-response association could become habitual, leading to four qualitatively different phenotypes, beyond being simply 'habitual' or 'nonhabitual'. (C) In general, behaviors may be generated based on a complex set of computations that relate a stimulus to an ultimate response (Figure 4 for an illustrative example), and any subset of these intermediate computations could become habitual. 


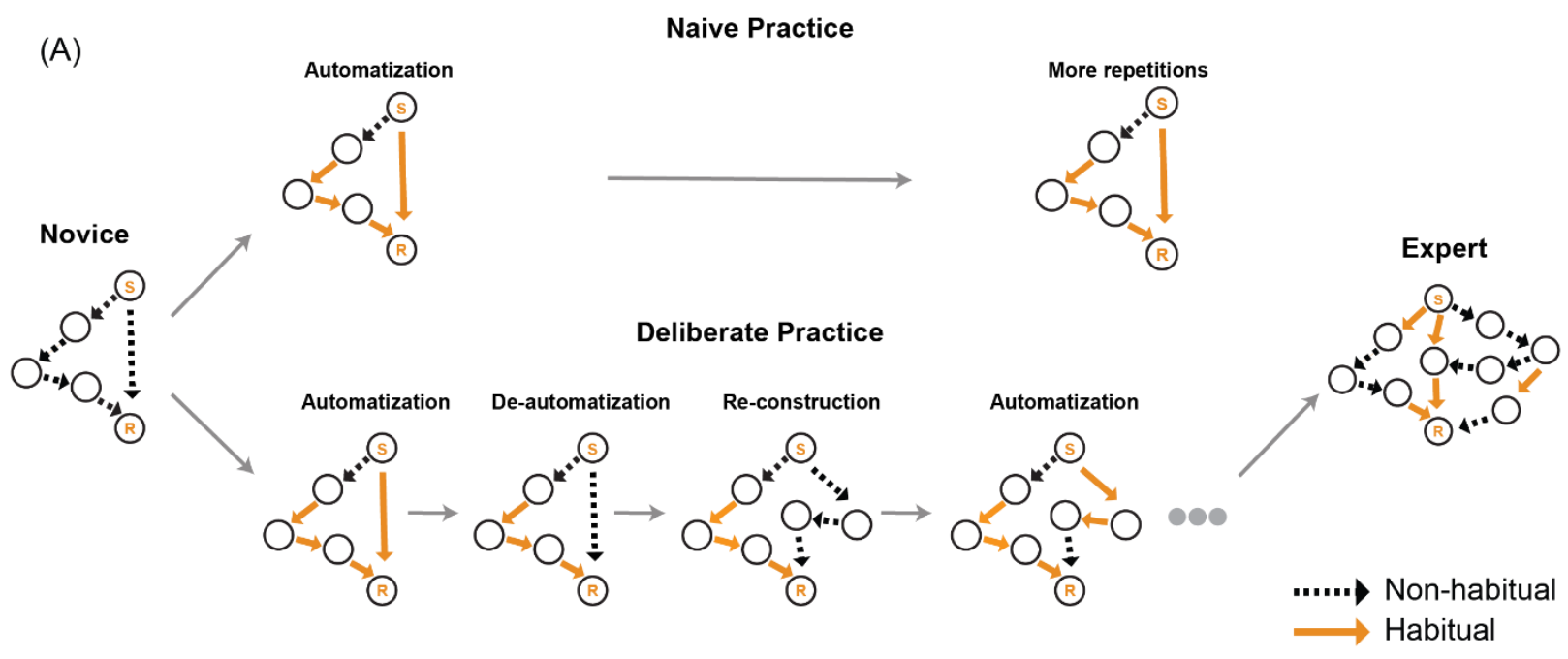

(B)
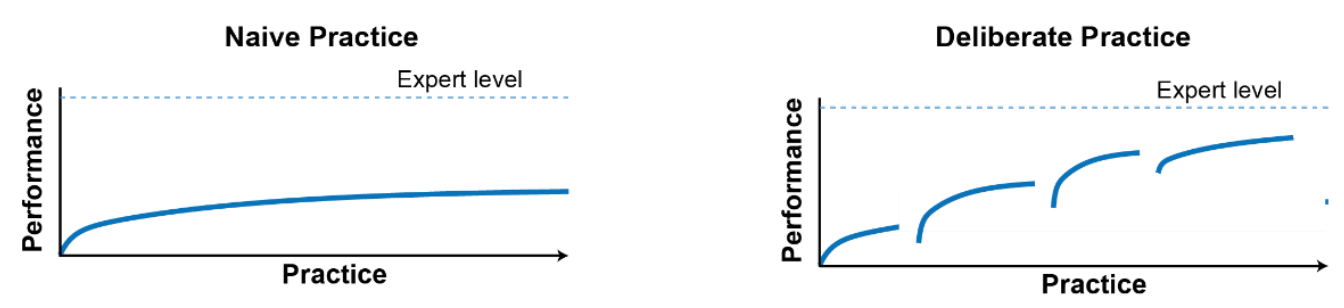

Figure 6: Learning complex skills through practice. (A) Practicing a new skill quickly leads to some components becoming automatized or, equivalently, being rendered habitual. This qualitative change allows us to focus cognitive resources on learning or improving other components of the skill. There are two distinct ways in which our performance can continue to improve further. In the upper row (naive practice), already automatized skills or their components can continue to improve through repetition, but the performance gains are likely to be limited and this type of practice is unlikely to lead to a high level of skill (B). In the lower row (deliberate practice), to achieve more substantial improvements in performance, it may be necessary to more drastically reorganize the way in which a task is performed, potentially introducing new computations. This will require de-automatizing specific components, rendering them back into a deliberate mode, so as to learn a restructured set of computations that lead to the selection of better responses. This restructured response can then be automatized again and refined through practice. Repeated cycles of building, breaking, and restructuring temporary automatic components (or, equivalently, habits) in this way is essential for maximizing one's skill level. (B) Schematic illustration of how the skill level improves under naive versus deliberate practice. Abbreviation: $R$, response; $S$, stimulus. 
1 James, W. (1890) The principles of psychology, Macmillan London.

2 Barandiaran, X.E. and Di Paolo, E.A. (2014) A genealogical map of the concept of habit. Front. Hum. Neurosci. 8, 522

3 Bernacer, J. and Murillo, J.I. (2014) The Aristotelian conception of habit and its contribution to human neuroscience. Front. Hum. Neurosci. 8, 883

4 Douskos, C. (2017) The spontaneousness of skill and the impulsivity of habit. Synthese

5 Graybiel, A.M. and Grafton, S.T. (2015) The striatum: where skills and habits meet. Cold Spring Harb. Perspect. Biol. 7, a021691

6 Haith, A.M. and Krakauer, J.W. (2018) The multiple effects of practice: skill, habit and reduced cognitive load. Curr. Opin. Behav. Sci. 20, 196-201

7 Sutton, J. et al. (2011) Applying intelligence to the reflexes: Embodied skills and habits between Dreyfus and Descartes. J. Br. Soc. Phenomenol. 42, 78-103

8 Fitts, P.M. and Posner, M.I. (1967) Human performance, Brooks and Cole.

9 Smith, K.S. and Graybiel, A.M. (2016) Habit formation. Dialogues Clin. Neurosci. 18, 33

10 Marien, H. et al. (2018) Understanding the formation of human habits: An analysis of mechanisms of habitual behaviour. In The psychology of habit (Verplanken, B., ed), pp. 51-69, Springer

11 Ryle, G. (2009) The concept of mind, Routledge.

12 Pear, T.H. (1928) The Nature of Skill. Nature

13 Squire, L.R. (1992) Declarative and nondeclarative memory - multiple brain systems supporting learning and memory. J. Cogn. Neurosci. 4, 232-243

14 Yin, H.H. and Knowlton, B.J. (2006) The role of the basal ganglia in habit formation. Nat. Rev. Neurosci. 7, 464-476

15 Daw, N.D. et al. (2005) Uncertainty-based competition between prefrontal and dorsolateral striatal systems for behavioral control. Nat. Neurosci. 8, 1704-1711

16 Desrochers, T.M. et al. (2010) Optimal habits can develop spontaneously through sensitivity to local cost. Proc. Natl. Acad. Sci. 107, 20512-20517

17 Haith, A.M. and Krakauer, J.W. (2013) Model-based and model-free mechanisms of human motor learning. In Progress in Motor Control: Neural Computational and Dynamic

Approaches (Richardson, M. J. et al., eds), pp. 1-21, Springer

18 Huang, V.S. et al. (2011) Rethinking motor learning and savings in adaptation paradigms: model-free memory for successful actions combines with internal models. Neuron 70, 787801

19 Miller, K.J. et al. (2019) Habits without values. Psychol. Rev.

20 Robbins, T.W. and Costa, R.M. (2017) Habits. Curr. Biol. 27, R1200-R1206

21 Clark, J.E. and Whitall, J. (2021) Motor development: A perspective on the past, the present, and the future. Kinesiol. Rev. 1, 264-273

22 Thelen, E. (1995) Motor development - a new synthesis. Am. Psychol. 50, 79-95

23 Whitall, J. et al. (2020) Motor development research: I. The lessons of history revisited (the 18th to the 20th century). J. Mot. Learn. Dev. 8, 345-362

24 Christensen, W. (2019) Skilled action. Philos. Compass 14, e12631

25 Krakauer, J.W. et al. (2019) Motor Learning. Compr. Physiol. 9, 613-663

26 Newell, K.M. (1985) Coordination, control and skill. In Advances in Psychology 27 (Goodman, D. et al., eds), pp. 295-317, Elsevier

27 Rosenbaum, D.A. et al. (2001) Acquisition of intellectual and perceptual-motor skills. Annu. Rev. Psychol. 52, 453-470 
28 Müller, H. and Sternad, D. (2004) Decomposition of variability in the execution of goaloriented tasks: three components of skill improvement. J. Exp. Psychol. Hum. Percept. Perform. 30, 212-233

29 Shmuelof, L. et al. (2012) How is a motor skill learned? Change and invariance at the levels of task success and trajectory control. J. Neurophysiol. 108, 578-594

30 Bernstein, N.A. (1967) The co-ordination and regulation of movements, Pergamon Press.

31 Manohar, S.G. et al. (2019) Motivation dynamically increases noise resistance by internal feedback during movement. Neuropsychologia 123, 19-29

32 Shmuelof, L. et al. (2014) The neural correlates of learned motor acuity. J. Neurophysiol. 112, 971-980

33 Elangovan, N. et al. (2017) A robot-aided visuo-motor training that improves proprioception and spatial accuracy of untrained movement. Sci. Rep. 7, 17054

34 Diedrichsen, J. and Kornysheva, K. (2015) Motor skill learning between selection and execution. Trends Cogn. Sci. 19, 227-233

35 Fagg, A.H. et al. (2002) A computational model of muscle recruitment for wrist movements. J. Neurophysiol. 88, 3348-3358

36 Haith, A.M. and Krakauer, J.W. (2013) Model-based and model-free mechanisms of human motor learning. In Progress in motor control pp. 1-21, Springer

37 Sternad, D. (2018) It's not (only) the mean that matters: variability, noise and exploration in skill learning. Curr. Opin. Behav. Sci. 20, 183-195

38 Wickelgren, W.A. (1977) Speed-accuracy tradeoff and information processing dynamics. Acta Psychol. (Amst.) 41, 67-85

39 Hardwick, R.M. et al. (2019) Time-dependent competition between goal-directed and habitual response preparation. Nat. Hum. Behav.

40 Reis, J. et al. (2009) Noninvasive cortical stimulation enhances motor skill acquisition over multiple days through an effect on consolidation. Proc. Natl. Acad. Sci. U. S. A. 106, 15901595

41 Gibson, J.J. (2014) The ecological approach to visual perception: classic edition, Psychology Press.

42 Kugler, P. et al. (1982) On the control and coordination of naturally developing systems. Dev. Mov. Control Coord.

43 Kugler, P.N. et al. (1980) On the concept of coordinative structures as dissipative structures: I. theoretical lines of convergence. In Advances in psychology 1 (Stelmach, G. E. and Requin, J., eds), pp. 3-47, Elsevier

44 Arsal, G. et al. (2016) Cognitive mediation of putting: Use of a think-aloud measure and implications for studies of golf-putting in the laboratory. Psychol. Sport Exerc. 27, 18-27

45 Christensen, W. et al. (2016) Cognition in skilled action: Meshed control and the varieties of skill experience. Mind Lang. 31, 37-66

46 Fridland, E. (2017) Skill and motor control: intelligence all the way down. Philos. Stud. $174,1539-1560$

47 Fridland, E. (2019) Longer, smaller, faster, stronger: On skills and intelligence. Philos. Psychol.

48 Stanley, J. and Krakauer, J.W. (2013) Motor skill depends on knowledge of facts. Front. Hum. Neurosci. 7, 503

49 Williams, M. et al. (1993) Cognitive knowledge and soccer performance. Percept. Mot. Skills 76, 579-593 
50 Chase, W.G. and Simon, H.A. (1973) The mind's eye in chess. In Visual information processing (Chase, W. G., ed), pp. 215-281, Elsevier

51 Toner, J. et al. (2015) Considering the role of cognitive control in expert performance. Phenomenol. Cogn. Sci. 14, 1127-1144

52 McDougle, S.D. et al. (2016) Taking aim at the cognitive side of learning in sensorimotor adaptation tasks. Trends Cogn. Sci. 20, 535-544

53 Brady, F. (1998) A theoretical and empirical review of the contextual interference effect and the learning of motor skills. Quest 50, 266-293

54 Wulf, G. and Shea, C.H. (2002) Principles derived from the study of simple skills do not generalize to complex skill learning. Psychon. Bull. Rev. 9, 185-211

55 Gray, W.D. and Lindstedt, J.K. (2017) Plateaus, dips, and leaps: Where to look for inventions and discoveries during skilled performance. Cogn. Sci. 41, 1838-1870

56 Haar, S. et al. (2020) Motor learning in real-world pool billiards. Sci. Rep. 10, 20046

57 Listman, J.B. et al. (2021) Long-Term Motor Learning in the "Wild" With High Volume Video Game Data. Front. Hum. Neurosci. 15, 769

58 Stafford, T. and Dewar, M. (2014) Tracing the trajectory of skill learning with a very large sample of online game players. Psychol. Sci. 25, 511-518

59 Stafford, T. and Vaci, N. (2022) Maximizing the potential of digital games for understanding skill acquisition. Curr. Dir. Psychol. Sci. DOI: https://doi.org/10.1177/09637214211057841

60 Thompson, J.J. et al. (2019) Classic motor chunking theory fails to account for behavioural diversity and speed in a complex naturalistic task. PloS One 14, e0218251

61 Muller, H. and Sternad, D. (2009) Motor learning: Changes in the structure of variability in a redundant task. In Progress in Motor Control: a Multidisciplinary Perspective 629 (Sternad, D., ed), pp. 439-456, Springer

62 Ranganathan, R. et al. (2013) Learning to be Lazy: Exploiting Redundancy in a Novel Task to Minimize Movement-Related Effort. J. Neurosci. 33, 2754-2760

63 Yang, C.S. et al. (2021) De novo learning versus adaptation of continuous control in a manual tracking task. eLife 10, e62578

64 Opheusden, B. van et al. Revealing the impact of expertise on human planning with a twoplayer board game. . 02-Feb-(2021), PsyArXiv

65 Nasseroleslami, B. et al. (2014) Rhythmic Manipulation of Objects with Complex Dynamics: Predictability over Chaos. PLOS Comput. Biol. 10, e1003900

66 Balleine, B.W. (2019) The meaning of behavior: discriminating reflex and volition in the brain. Neuron 104, 47-62

67 Dickinson, A. and Pérez, O.D. (2018) Actions and habits: Psychological issues in dualsystem theory. In Goal-Directed Decision Making (Morris, R. et al., eds), pp. 1-25, Elsevier

68 Adams, C.D. (1982) Variations in the sensitivity of instrumental responding to reinforcer devaluation. Q. J. Exp. Psychol. Sect. B 34, 77-98

69 Dickinson, A. (1985) Actions and habits: the development of behavioural autonomy. Philos. Trans. R. Soc. Lond. B Biol. Sci. 308, 67-78

70 Everitt, B.J. and Robbins, T.W. (2005) Neural systems of reinforcement for drug addiction: from actions to habits to compulsion. Nat. Neurosci. 8, 1481-1489

71 Watson, P. and de Wit, S. (2018) Current limits of experimental research into habits and future directions. Curr. Opin. Behav. Sci. 20, 33-39 
72 Wood, W. and Rünger, D. (2016) Psychology of habit. Annu. Rev. Psychol. 67, 289-314

73 Colwill, R.M. and Rescorla, R.A. (1985) Instrumental responding remains sensitive to reinforcer devaluation after extensive training. J. Exp. Psychol. Anim. Behav. Process. 11, $520-536$

74 Hogarth, L. (2018) A critical review of habit theory of drug dependence. In The psychology of habit (Verplanken, B., ed), pp. 325-341, Springer

75 de Wit, S. et al. (2018) Shifting the balance between goals and habits: Five failures in experimental habit induction. J. Exp. Psychol. Gen. 147, 1043-1065

76 Tricomi, E. et al. (2009) A specific role for posterior dorsolateral striatum in human habit learning. Eur. J. Neurosci. 29, 2225-2232

77 Seger, C.A. and Spiering, B.J. (2011) A critical review of habit learning and the basal ganglia. Front. Syst. Neurosci. 5, 66

78 De Houwer, J. et al. (2018) Kicking the habit: Why evidence for habits in humans might be overestimated. Motiv. Sci. 4, 50

79 De Houwer, J. (2019) On How Definitions of Habits Can Complicate Habit Research. Front. Psychol. 10,

80 Hommel, B. (2019) Binary theorizing does not account for action control. Front. Psychol. 10,2542

81 Hommel, B. and Wiers, R.W. (2017) Towards a unitary approach to human action control. Trends Cogn. Sci. 21, 940-949

82 Carder, B. and Berkowitz, K. (1970) Rats' preference for earned in comparison with free food. Science 167, 1273-1274

83 Holland, P.C. (2008) Cognitive versus stimulus-response theories of learning. Learn. Behav. 36, 227-241

84 Colwill, R.M. and Rescorla, R.A. (1986) Associative structures in instrumental learning. In Psychology of learning and motivation 20 (Bower, G. H., ed), pp. 55-104, Elsevier

85 Thorndike, E.L. (1911) Animal intelligence: Experimental studies, Macmillan.

86 Piray, P. and Daw, N.D. (2021) Linear reinforcement learning in planning, grid fields, and cognitive control. Nat. Commun. 12, 4942

87 Mylopoulos, M. (2021) Oops! I did it again: the psychology of everyday action slips. Top. Cogn. Sci. DOI: https://doi.org/10.1111/tops. 12552

88 Norman, D.A. (1981) Categorization of action slips. Psychol. Rev. 88, 1-15

89 Toner, J. et al. (2015) The perils of automaticity. Rev. Gen. Psychol. 19, 431-442

90 Grol, M.J. et al. (2009) Spatial representation of overlearned arbitrary visuomotor associations. Exp. Brain Res. 192, 751-759

91 Wise, S.P. and Murray, E.A. (2000) Arbitrary associations between antecedents and actions. Trends Neurosci. 23, 271-276

92 Ashby, F.G. and Crossley, M.J. (2012) Automaticity and multiple memory systems. Wiley Interdiscip. Rev. Cogn. Sci. 3, 363-376

93 Ceceli, A.O. et al. (2020) Demonstrating and disrupting well-learned habits. PloS One 15, e0234424

94 Hélie, S. et al. (2010) Automaticity in rule-based and information-integration categorization. Atten. Percept. Psychophys. 72, 1013-1031

95 Luque, D. et al. (2020) Measuring habit formation through goal-directed response switching. J. Exp. Psychol. Gen. 149, 1449-1459 
96 Wood, W. et al. (2021) Habits and Goals in Human Behavior: Separate but Interacting Systems. Perspect. Psychol. Sci. DOI: https://doi.org/10.1177/1745691621994226

97 Wood, W. and Neal, D.T. (2007) A new look at habits and the habit-goal interface. Psychol. Rev. 114, 843-863

98 Kruglanski, A.W. and Szumowska, E. (2020) Habitual behavior is goal-driven. Perspect. Psychol. Sci. 15, 1256-1271

99 Douskos, C. (2018) Deliberation and automaticity in habitual acts. Ethics Prog. 9, 25-43

100 Aarts, H. and Dijksterhuis, A. (2000) Habits as knowledge structures: Automaticity in goaldirected behavior. J. Pers. Soc. Psychol. 78, 53-63

101 Cushman, F. and Morris, A. (2015) Habitual control of goal selection in humans. Proc. Natl. Acad. Sci. 112, 13817-13822

102 Buabang, E.K. et al. A goal-directed account of action slips: The reliance on old contingencies. PsyArXiv DOI: http://dx.doi.org/10.31234/osf.io/y6vbg

103 Daw, N.D. (2015) Of goals and habits. Proc. Natl. Acad. Sci. 112, 13749-13750

104 Vandaele, Y. and Janak, P.H. (2018) Defining the place of habit in substance use disorders. Prog. Neuropsychopharmacol. Biol. Psychiatry 87, 22-32

105 Colwill, R.M. (1994) Associative representations of instrumental contingencies. Psychol. Learn. Motiv. Adv. Res. Theory 31, 1-72

106 Colwill, R.M. and Rescorla, R.A. (1990) Evidence for the hierarchical structure of instrumental learning. Anim. Learn. Behav. 18, 71-82

107 Collins, A.G. and Frank, M.J. (2013) Cognitive control over learning: creating, clustering, and generalizing task-set structure. Psychol. Rev. 120, 190-229

108 Eckstein, M.K. and Collins, A.G. (2020) Computational evidence for hierarchically structured reinforcement learning in humans. Proc. Natl. Acad. Sci. 117, 29381-29389

109 Monsell, S. (2017) Task set regulation. In The Wiley handbook of cognitive control (Egner, T., ed), pp. 29-49, Wiley Blackwell

110 Badre, D. and Nee, D.E. (2018) Frontal cortex and the hierarchical control of behavior. Trends Cogn. Sci. 22, 170-188

111 Botvinick, M.M. (2008) Hierarchical models of behavior and prefrontal function. Trends Cogn. Sci. 12, 201-208

112 Cooper, R. and Shallice, T. (2000) Contention scheduling and the control of routine activities. Cogn. Neuropsychol. 17, 297-338

113 Norman, D.A. and Shallice, T. (1986) Attention to action. In Consciousness and selfregulation (Davidson, R. J. et al., eds), pp. 1-18, Springer

114 Tomov, M.S. et al. (2020) Discovery of hierarchical representations for efficient planning. PLoS Comput. Biol. 16, e1007594

115 Trach, J.E. et al. (2021) Abstract sequential task control is facilitated by practice and embedded motor sequences. J. Exp. Psychol. Learn. Mem. Cogn.

116 Gardner, B. et al. (2016) Habitual instigation and habitual execution: Definition, measurement, and effects on behaviour frequency. Br. J. Health Psychol. 21, 613-630

117 Gardner, B. et al. (2020) 'Habitually deciding' or 'habitually doing'? A response to Hagger (2019). Psychol. Sport Exerc. 47, 101539

118 Phillips, L.A. and Gardner, B. (2016) Habitual exercise instigation (vs. execution) predicts healthy adults' exercise frequency. Health Psychol. 35, 69-77

119 Rhodes, R.E. and Rebar, A.L. (2018) Physical activity habit: Complexities and controversies. In The psychology of habit (Verplanken, B., ed), pp. 91-109, Springer 
120 Keramati, M. et al. (2016) Adaptive integration of habits into depth-limited planning defines a habitual-goal-directed spectrum. Proc. Natl. Acad. Sci. 113, 12868-12873

121 Morris, A. and Cushman, F. (2019) Model-Free RL or Action Sequences? Front. Psychol. 10,2892

122 Hélie, S. and Cousineau, D. (2011) The cognitive neuroscience of automaticity: behavioral and brain signatures. Cogn. Sci. 6, 35-53

123 Smith, K.S. and Graybiel, A.M. (2013) A dual operator view of habitual behavior reflecting cortical and striatal dynamics. Neuron 79, 361-374

124 Sternberg, S. (1969) The discovery of processing stages: Extensions of Donders' method. Acta Psychol. (Amst.) 30, 276-315

125 Wong, A.L. et al. (2015) Motor planning. The Neuroscientist 21, 385-398

126 Henson, R.N. et al. (2014) Stimulus-response bindings in priming. Trends Cogn. Sci. 18, 376-384

127 Lu, C.H. and Proctor, R.W. (1995) The influence of irrelevant location information on performance: A review of the Simon and spatial Stroop effects. Psychon. Bull. Rev. 2, 174207

128 Cisek, P. (2012) Making decisions through a distributed consensus. Curr. Opin. Neurobiol. 22, 927-936

129 Cisek, P. and Kalaska, J.F. (2010) Neural mechanisms for interacting with a world full of action choices. Annu. Rev. Neurosci. 33, 269-298

130 Schmidt, R.A. (1975) A schema theory of discrete motor skill learning. Psychol. Rev. 82, 225-260

131 Schmidt, R.A. (2003) Motor schema theory after 27 years: Reflections and implications for a new theory. Res. Q. Exerc. Sport 74, 366-375

132 Stoloff, R. et al. (2011) Effect of Reinforcement History on Hand Choice in an Unconstrained Reaching Task. Front. Neurosci. 5, 41

133 Mazzoni, P. et al. (2007) Why don't we move faster? Parkinson's disease, movement vigor, and implicit motivation. J. Neurosci. 27, 7105-7116

134 De Rugy, A. et al. (2012) Muscle coordination is habitual rather than optimal. J. Neurosci. 32, 7384-7391

135 Gordon, A.M. et al. (1994) The learning of novel finger movement sequences. $J$. Neurophysiol. 72, 1596-1610

136 Kelso, J.A. (1984) Phase transitions and critical behavior in human bimanual coordination. Am. J. Physiol.-Regul. Integr. Comp. Physiol. 246, R1000-R1004

137 Mannell, R.C. and Duthie, J.H. (1975) Habit lag: When "automatization" is dysfunctional. J. Psychol. 89, 73-80

138 Summers, J.J. (1975) The role of timing in motor program representation. J. Mot. Behav. 7, 229-241

139 Verstynen, T. and Sabes, P.N. (2011) How Each Movement Changes the Next: An Experimental and Theoretical Study of Fast Adaptive Priors in Reaching. J. Neurosci. 31, 10050-10059

140 Hammerbeck, U. et al. (2013) Movement speed is biased by prior experience. $J$. Neurophysiol. 111, 128-134

141 Wong, A.L. et al. (2017) Reaction times can reflect habits rather than computations. Elife 6, $\mathrm{e} 28075$ 
142 Rueda-Orozco, P.E. and Robbe, D. (2015) The striatum multiplexes contextual and kinematic information to constrain motor habits execution. Nat. Neurosci. 18, 453-460

143 MacLeod, C.M. (1991) Half a century of research on the Stroop effect: an integrative review. Psychol. Bull. 109, 163-203

144 Bargh, J.A. (1994) The four horsemen of automaticity: Awareness, intention, efficiency, and control in social cognition. Handb. Soc. Cogn. 1, 1-40

145 Moors, A. (2016) Automaticity: Componential, causal, and mechanistic explanations. Annu. Rev. Psychol. 67, 263-287

146 Moors, A. and De Houwer, J. (2006) Automaticity: a theoretical and conceptual analysis. Psychol. Bull. 132, 297-326

147 Shiffrin, R.M. and Dumais, S.T. (1981) The development of automatism. In Cognitive skills and their acquisition (Anderson, J. R., ed), pp. 111-140, Routledge

148 Gardner, B. (2012) Habit as automaticity, not frequency. Eur. Health Psychol. 14, 32-36

149 Logan, G.D. (1988) Toward an instance theory of automatization. Psychol. Rev. 95, 492527

150 Anderson, J.R. (1992) Automaticity and the ACT theory. Am. J. Psychol. 105, 165-180

151 Schneider, W. and Shiffrin, R.M. (1977) Controlled and automatic human information processing: I. Detection, search, and attention. Psychol. Rev. 84, 1-66

152 Shiffrin, R.M. and Schneider, W. (1977) Controlled and automatic human information processing: II. Perceptual learning, automatic attending and a general theory. Psychol. Rev. 84, 127-190

153 Tzelgov, J. et al. (2000) Automatic comparisons of artificial digits never compared: learning linear ordering relations. J. Exp. Psychol. Learn. Mem. Cogn. 26, 103-120

154 Carlson, R.A. and Lundy, D.H. (1992) Consistency and restructuring in learning cognitive procedural sequences. J. Exp. Psychol. Learn. Mem. Cogn. 18, 127-141

155 Ranganathan, R. et al. (2020) Repetition Without Repetition: Challenges in Understanding Behavioral Flexibility in Motor Skill. Front. Psychol. 11, 2018

156 Demos, A.P. et al. (2016) Flexibility of expressive timing in repeated musical performances. Front. Psychol. 7, 1490

157 Fridland, E. (2017) Automatically minded. Synthese 194, 4337-4363

158 Pacherie, E. and Mylopoulos, M. (2020) Beyond automaticity: The psychological complexity of skill. Topoi

159 Toner, J. and Moran, A. (2020) Exploring the orthogonal relationship between controlled and automated processes in skilled action. Rev. Philos. Psychol.

160 Gershman, S.J. et al. (2015) Computational rationality: A converging paradigm for intelligence in brains, minds, and machines. Science 349, 273-278

161 Lieder, F. and Griffiths, T.L. (2019) Resource-rational analysis: understanding human cognition as the optimal use of limited computational resources. Behav. Brain Sci. DOI: 10.1017/S0140525X1900061X

162 Taylor, J.A. and Ivry, R.B. (2012) The role of strategies in motor learning. Ann. N. Y. Acad. Sci.

163 Ericsson, K.A. (2006) The influence of experience and deliberate practice on the development of superior expert performance. Camb. Handb. Expert. Expert Perform. 38, 685-703

164 Ericsson, K.A. (2018) The differential influence of experience, practice, and deliberate practice on the development of superior individual performance of experts. In The 
Cambridge handbook of expertise and expert performance (Ericsson, K. A. and Hoffman, R. R., eds), pp. 745-769, Cambridge University Press

165 Ericsson, K.A. et al. (1993) The role of deliberate practice in the acquisition of expert performance. Psychol. Rev. 100, 363-406

166 Popp, N.J. et al. (2020) The effect of instruction on motor skill learning. J. Neurophysiol. $124,1449-1457$

167 Huang, V.S. et al. (2008) Active learning: learning a motor skill without a coach. $J$. Neurophysiol. 100, 879-887

168 Huys, Q.J. et al. (2015) Interplay of approximate planning strategies. Proc. Natl. Acad. Sci. $112,3098-3103$

169 Ericsson, K.A. (1998) The scientific study of expert levels of performance: General implications for optimal learning and creativity. High Abil. Stud. 9, 75-100

170 Ericsson, K.A. (2007) Deliberate practice and the modifiability of body and mind: Toward a science of the structure and acquisition of expert and elite performance. Int. J. Sport Psychol. 38, 4-34

171 Foerde, K. (2018) What are habits and do they depend on the striatum? A view from the study of neuropsychological populations. Curr. Opin. Behav. Sci. 20, 17-24

172 Grol, M.J. et al. (2006) Cerebral changes during performance of overlearned arbitrary visuomotor associations. J. Neurosci. 26, 117-125

173 Poldrack, R.A. et al. (2005) The neural correlates of motor skill automaticity. J. Neurosci. $25,5356-5364$

174 Krakauer, J.W. et al. (2017) Neuroscience needs behavior: correcting a reductionist bias. Neuron 93, 480-490

175 Niv, Y. (2021) The primacy of behavioral research for understanding the brain. Behav. Neurosci. 135, 601-609

176 Caruana, F. and Testa, I. (2020) Habits: Pragmatist Approaches from Cognitive Science, Neuroscience, and Social Theory, Cambridge University Press.

177 Verplanken, B. (2018) Psychology of Habit, Springer.

178 Graybiel, A.M. (2008) Habits, rituals, and the evaluative brain. Annu Rev Neurosci 31, 359-387

179 Gardner, B. (2015) A review and analysis of the use of 'habit'in understanding, predicting and influencing health-related behaviour. Health Psychol. Rev. 9, 277-295

180 Verplanken, B. and Orbell, S. (2003) Reflections on past behavior: a self-report index of habit strength 1. J. Appl. Soc. Psychol. 33, 1313-1330

181 Phillips, L.A. (2020) Challenging assumptions about habit: A response to Hagger (2019). Psychol. Sport Exerc. 47, 101502 